\title{
TLC/IR (UATR) off-line coupling for the characterization of additives in EPDM rubber compositions
}

\author{
Denis Damazio ${ }^{1,2}$, Eunice Aparecida Campos ${ }^{1,3}$, Milton Faria Diniz ${ }^{3}$, Elizabeth da Costa Mattos ${ }^{1,3}$ \\ and Rita de Cássia Lazzarini Dutra ${ }^{1 *}$ \\ 1'Instituto Tecnológico de Aeronáutica - ITA, São José dos Campos, SP, Brazil \\ 'Zanaflex Compostos de Borracha, Cotia, SP, Brazil \\ ${ }^{3}$ Divisão de Química - AQI, Instituto de Aeronáutica e Espaço - IAE, São José dos Campos, SP, Brazil \\ *ritacld@ita.br
}

\begin{abstract}
The knowledge of the components that constitutes a rubber composition is important to justify the properties of the final device, particularly when it comes to elastomeric compositions used in the aerospace industry. The development of methodologies that can detect components, specially the smallest proportion of the rubbers composition is a constant challenge and an important gap in the studies of this nature. Therefore, methodologies by using standard techniques and/or of last generation are important in rubber industry and research laboratories, aiming application in related research. In this context, this study shows the coupling/association techniques (off-line) of thin layer chromatography and infrared spectroscopy (TLC/IR), being the IR spectra obtained by universal attenuated total reflection (UATR), applied to the analysis of additives in rubber compositions of ethylene-propylene-diene rubber (EPDM). Two EPDM compositions, a kind of eluent system and Gibbs' reagent, as developer, were used. Basically, all organic components were detected by this methodology, being possible to suggest that it can be applied for detecting additives of similar chemical structures, even though it's presents in small amounts in the composition.
\end{abstract}

Keywords: additives, EPDM, TLC/IR off-line coupling, UATR.

\section{Introduction}

The determination of the additive in polymers compositions in general by instrumental techniques, undergoes a preliminary extraction step. However, unambiguous identification of these components is not always possible, when analyzed by spectroscopic techniques, such as infrared spectroscopy (IR), due to the interference of other additives bands ${ }^{[1]}$.

The research of different industrial goals requires the development of compositions containing plasticizers, accelerators and other additives, which may also form secondary products, increasing the complexity of the determination. The knowledge of the origin of the polymeric material, its application and suitable composition, are important data for the development of analytical methodology, for the characterization of these additives. A separation technique is needed to compose this methodology in the search for greater accuracy in obtaining results ${ }^{[2]}$.

Thin layer chromatography (TLC) is a well known technique for separating components of a mixture and characterize unknown materials by comparison of the characteristics (color and reference- factor RF) of its separated products, related to reference materials, which must be shown in the composition ${ }^{[3]}$.

TLC has advantages such as: speed, simplicity and low cost, it can be used in different laboratories that awakes greater interest of the industry and can be a useful tool for the scientific community. However, it is necessary to find suitable conditions for determining, which is not always a simple task ${ }^{[2,3]}$.
IR spectroscopy, a well known technique ${ }^{[4]}$, whose greatest quality is the identification of chemical function compounds, has been used quite successfully by many researchers, and in the laboratories of Instituto de Aeronáutica e Espaço (IAE), in particular, for analysis of rubber based on copolymer of ethylene-propylene-diene (EPDM), used in aerospace researches ${ }^{[5-7]}$.

Regarding the analysis data of additives in rubber, papers have also been published by the IAE group, and among them some stand out, the use of liquid chromatography high performance (HPLC) and IR spectroscopy applied to study of rubber additives ${ }^{[8]}$ in known composition on polychlorosulfoethylene (Hypalon) (CSM), and butadiene-styrene copolymer (SBR) of unknown composition, and the application of technical coupling association of TLC/IR ${ }^{[2]}$ for the study of rubbers.

In the study ${ }^{[8]}$, HPLC was used as a components separation technique, being confirmed by IR analysis of the CSM composition, the presence of tetramethylthiuram disulfide (TMTD). Mercaptobenzotialzol disulfide (MBTS) was not detected by IR, according to the authors, probably due to this compound is in lower content in the composition of rubber, therefore it was possible to confirm the presence of additives by HPLC with ultraviolet detection (UV). For SBR rubber, could be detected by IR, the presence of amine antioxidant, based on likely to diphenylamine and naphthenic oil. The presence of amine antioxidant, based on the similiarity chemical structure to diphenylamine and naphthenic oil, could be detected by IR in the SBR rubber. 
HPLC analysis was not effective in this case. Thus, these techniques were complementary, in order to identify the greatest number of additives in the composition.

Although some details of the compositions studied have been raised by this study ${ }^{[8]}$, it is understood that complex method was used according to the conditions available, because HPLC analysis required several injections resulting in considerable time analysis.

Dutra $^{[2]}$ described the TLC-IR coupling techniques as useful for the separation and identification of additives and uses two types of methods, one of pyramids including potassium bromide $(\mathrm{KBr})$ and other simpler but also using $\mathrm{KBr}$, developed in the laboratories of the IAE. It was observed that the application of this coupling or combination of techniques was made only using IR transmission techniques, with laboratory resources available during the study period. But, we think that is possible to include in to this study the use of reflection techniques.

Recently, another study ${ }^{[5]}$, Fourier transform infrared spectroscopy (FT-IR) was employed to investigate the gaseous products of EPDM. The potential of FT-IR analysis of gaseous pyrolyzates, named PY-G/FT-IR, for characterization of EPDM additives, was evaluated. Two EPDM compositions were analyzed. Initially, gaseous pyrolysis products from paraffinic oil, stearic acid, 2,2,4-trimethyl1,2-dihydroquinoline, tetramethylthiuram monosulfide (TMTM), TMTD, and 2-mercaptobenzothiazole (MBT) were characterized separately, and their main IR bands were identified. Subsequently, the gaseous pyrolysis products of three kinds of EPDM compositions, raw, unvulcanized, and vulcanized, were analyzed. The similarities observed in the FT-IR spectra of unvulcanized and vulcanized EPDM show that the vulcanization process does not interfere with the pyrolysis products. The identification of the functional groups of the studied additives was possible in both unvulcanized and vulcanized EPDM samples, without solvent extraction. It was possible to demonstrate that the PY-G/FT-IR technique can identify additives containing sulfur in concentrations as low as $1.4 \mathrm{phr}$ in both unvulcanized and vulcanized EPDM. However, the methodology showed some limitations due to overlapping and similarities of TMTM and TMTD PY-G/FT-IR spectra, which could not be distinguished from each other.

Sanches et al. ${ }^{[5]}$ considered that the PY-G/FT-IR is a faster and cheaper alternative technique compared to the sophisticated techniques usually applied to detection of additives in rubbers. However other techniques, such as TLC-IR, also can be applied to reach this goal.

TLC association with the reflection techniques, used in Fourier transform spectroscopy (FT-IR), has been cited in the literature ${ }^{[9,10]}$. In these studies, by using reflection techniques, although it has been highlighted the diffuse reflectance (DRIFT), it was mentioned that there were difficulties related to time of analysis and interference of absorptions of materials used in DRIFT-TLC analysis, such as silica present on the TLC plate, with those relating to additives to be identified. Recently, FT-IR microscopy technique ${ }^{[11]}$, have been focused as more promising, but we think that other reflection techniques, less complex and quicker can be used, such as universal attenuated total reflection (UATR), which has been used successfully to polymer analysis at IAE laboratories ${ }^{[6]}$.

Therefore, in this paper, it was evaluated the applicability of the coupling/association TLC/IR techniques for the analysis of two EPDM rubber compositions, aiming to contribute to increase for increasing the knowledge for characterization of additives in rubber by potential reflection techniques, such as UATR.

\section{Materials and Methods}

The samples used in the compositions of EPDM-were kindly supplied by the company Zanaflex Borrachas. In Table 1, the components of composition and the quantities (phr) are included, of the EPDM rubber compositions ${ }^{[12]}$, numbers $\mathbf{1}$ and 2, with small content of components for internal purposes. After the development of the composition, samples were cured ${ }^{[10]}$ with $2 \mathrm{~mm}$ thick plates per $10 \mathrm{~cm}$ of width and length, during 30 minutes at $160{ }^{\circ} \mathrm{C}$.

\subsection{Methodology / extraction}

The initial separation of organic additives EPDM of the two compositions was done by using auxiliary techniques, such as Soxhlet extraction with suitable solvent, acetone ${ }^{[13]}$. The material, about $0.5 \mathrm{~g}$, to be extracted was cut into small pieces and wrapped in filter paper and inserted to the extracting system. The time used for the extraction was 8 hours, and the solvent was evaporated under mild conditions.

\subsection{TLC/IR analysis}

In an attempt to separate the organic additives, soluble in acetone, TLC technique has been used with Merck chromatography plate, $20 \mathrm{~cm}$ and it recovered with a layer of silica gel 60 . The plate was marked in 0.78 inches for the upper and $0.39 \mathrm{~cm}$ for the lower, to limit the amount of eluent to be added in the glass tank ${ }^{[2]}$. In the chromatography plate was added $15 \mu \mathrm{L}$ of the extract obtained ${ }^{[2]}$ and the additives, taken as a reference: stearic acid, TMTD, MBT,TMTM, TMQ and paraffinic oil, being necessary to solubilize the

Table 1. EPDM rubber compositions (1 and 2).

\begin{tabular}{lcc}
\hline & Composition & Composition \\
\multicolumn{1}{c}{ Componentes } & ( & 2hr) \\
\hline EPDM (Keltan 2340A) & 100 & (phr) \\
EPDM (Keltan 21) & - & - \\
Zinc oxide & 5.0 & 100 \\
Sulfur & 1.5 & 2.0 \\
Stearic acid & 1.0 & 0.7 \\
Carbon black & 80 & 0.5 \\
Paraffinic oil & 50 & 5.0 \\
MBT (mercaptobenzothiazole) & 0.5 & 1.0 \\
TMTD (Tetramethyl thiuram & 1.0 & 0.7 \\
disulfide) & & - \\
TMQ (2,2,4- •trimethyl-1,2- & -- & 1.0 \\
dihydroquinoline) & & \\
TMTM (Tetramethyl thiuram & & \\
monosulfide) & - & 0.7 \\
\hline
\end{tabular}


starting materials, in powder form, with a suitable solvent for the formation of liquid. Some analyzes were performed in duplicate to verify system repeatability.

After labeling and addition of materials, the plate was placed in the chromatography vessel saturated with the chosen eluent system, hexane, diethyl ether and acetic acid ${ }^{[14]}$ (70: 30: 5), in the $1 \mathrm{~cm}$ mark to occur the development of analysis $^{[2]}$.

After the run time, suitable for each system analyzed, the plate was removed and brought to $105^{\circ} \mathrm{C}$ for 30 minutes in an oven, and then cooled to room temperature. After the drying and cooling time, the plate was subjected to development with a suitable developer spots of $1 \%$ solution of 2,6-di-chloro-para-chloro benzoquinine imine (Gibbs reagent $)^{[2,12]}$, which acts revealing the colors, highlighting the differences of the analyzed additives.

Each additive was eluted by a certain height. For all the products analyzed, the ratio was measured height, in inches, of the eluted deposit average and total height of $16 \mathrm{~cm}$. This value is called retention factor (RF). The eluted deposit obtained on the plate was scraped and treated with the solvent used in the extraction, filtered and dried to remove silica ${ }^{[2]}$ and then analyzed by using FT-IR spectrometer SPECTRUM ONE PERKINELMER. The analysis conditions were: resolution: $4 \mathrm{~cm}^{-1}$; in the mid infrared (MIR), 4000 to $400 \mathrm{~cm}^{-1} ; 20$ scans, using the reflection accessory, UATR. The additives were also analyzed as received by UATR under the same conditions.

\section{Results and Discussions}

\subsection{UATR analysis of the organic additives as received}

Before proceeding to step methodology involving the extraction and characterization of the components by TLC / FT-IR, it is convenient to perform, initially, the characterization of the reference additives according to the same method of obtaining spectra, by UATR. Figure 1 shows the UATR spectra of composition additives and their structural formulas.

The main bands, assigned to its main functional groups ${ }^{[4,15]}$ are in $\left(\mathrm{cm}^{-1}\right)$ : a) MBT - 3108, 3070 and $3037(\mathrm{ArCH}), 1595$ and 1495 (ArCC), 1423 (C=N and/or C-S), 1319 and 1243 $(\mathrm{C}=\mathrm{N}, \mathrm{C}-\mathrm{N}$ and /or C-S), 1012 (ArC-S), $749(\mathrm{ArCH}) ; b)$ paraffinic oil - $2921\left(\mathrm{CH}_{2}\right), 2852\left(\mathrm{CH}_{2}\right), 1460\left(\mathrm{CH}_{3}, \mathrm{CH}_{2}\right)$, $1376\left(\mathrm{CH}_{3}\right)$ and $720\left(\mathrm{CH}_{2} \mathrm{n} \geq 3\right)$; c) stearic acid - 1698 (COOH), 1296 (CO), $720\left(\mathrm{CH}_{2} \mathrm{n} \geq 3\right)$; d) TMTD - 2933 $\left(\mathrm{CH}_{3}\right), 1370\left(\mathrm{CH}_{3}\right), 1232(\mathrm{C}=\mathrm{S}, \mathrm{C}-\mathrm{S}), 1145(\mathrm{C}-\mathrm{N}), 563(\mathrm{SS})$; e) TMQ - $3380(\mathrm{NH}), 3017(\mathrm{ArCH}), 2961\left(\mathrm{CH}_{3}\right), 2926$ e $2866\left(\mathrm{ArCH}_{3}\right), 1649 \mathrm{NH}, 1607(\mathrm{ArCH}), 1581(\mathrm{NH}), 1499$ $(\mathrm{ArCH}, \mathrm{CHN}), 1381$ and $1361\left(\mathrm{CH}_{3}\right.$ gem-dimethyl), 1260 and 1170 (ArC-N), 814 and 748 (ArC-H); f) TMTM - 1518 $(\mathrm{C}=\mathrm{S}, \mathrm{C}-\mathrm{N}), 1438,1249,1149,1052$ e $998(\mathrm{C}-\mathrm{S}, \mathrm{C}=\mathrm{S}$, $\mathrm{C}-\mathrm{N}), 1376\left(\mathrm{CH}_{3}\right)$.

\subsection{UATR analysis of extraction residue of the two EPDM compositions}

Since the method chosen for characterizing eluted spots on TLC/IR method was UATR, the extraction residues of EPDM rubber compositions 1 and 2 (Figure 2) were analyzed according to the same method, it constitutes the second step of the developed methodology.

The major bands observed $\left(\mathrm{cm}^{-1}\right)$ in UATR spectrum of the extract in acetone of composition 1 shows the presence of the functional groups ${ }^{[4]}: \mathrm{OH}\left(3400 \mathrm{~cm}^{-1}\right), \mathrm{CH}_{2}$ (2922 and 2853), $\mathrm{C}=\mathrm{O}$ (1713), $\mathrm{CH}_{2}$ and $\mathrm{CH}_{3}$ (1457), $\mathrm{CH}_{3}$ (1377), $\mathrm{C}-\mathrm{O}$ and/or C-S (1243), C-O (1164 and 1099) and $\mathrm{CH}_{2} \mathrm{n} \geq 3$ (720), suggesting that the residue consists essentially of aliphatic compound containing acid groups $(\mathrm{COOH}), \mathrm{CO}$ or $\mathrm{CS}$, and carbon chain with more than $3 \mathrm{CH}_{2}$ groups in accordance with some compounds present in the composition, such as stearic acid, TMTD, but, as expected, may there are overlapped bands, requiring a separation technique such as TLC, and other identification step, such as FT-IR technique, in trying to get a better result.

The major bands observed in UATR spectrum of the extract in acetone, composition 2, contains the wavenumbers $\left(\mathrm{cm}^{-1}\right)^{[4]}: 3373(\mathrm{OH}$ or $\mathrm{NH}), 2959\left(\mathrm{CH}_{3}\right), 2924$ and 2854 $\left(\mathrm{CH}_{2}\right), 1709(\mathrm{C}=\mathrm{O}), 1605$ and $1498(\mathrm{ArC}-\mathrm{C}$ and $\mathrm{CHN})$, $1461\left(\mathrm{CH}_{2}\right.$ and $\left.\mathrm{CH}_{3}\right), 1379$ e $1360\left(\mathrm{CH}_{3}\right.$ gem-dimethyl), 1319 (C-N and/or C=N), 1245 (C-O and/or C-S, C-N C=S), 1103 (C-O), 1015 (C-O and/or ArC-S), 815, 750 and 655 $(\mathrm{ArC}-\mathrm{H})$. This set of bands suggests that the residue of the composition 2, consisting primarily of aliphatic and aromatic compounds containing NH groups and CS, similar to those found in sulfur and amino compounds in the composition, such as MBT, TMQ and TMTM and also the presence of acid groups $\mathrm{COOH}$ and $\mathrm{CO}$. However, in the same manner as for the composition 1, may overlap bands, requiring the application of a separation technique such as TLC and an identification technique, such as FT-IR.

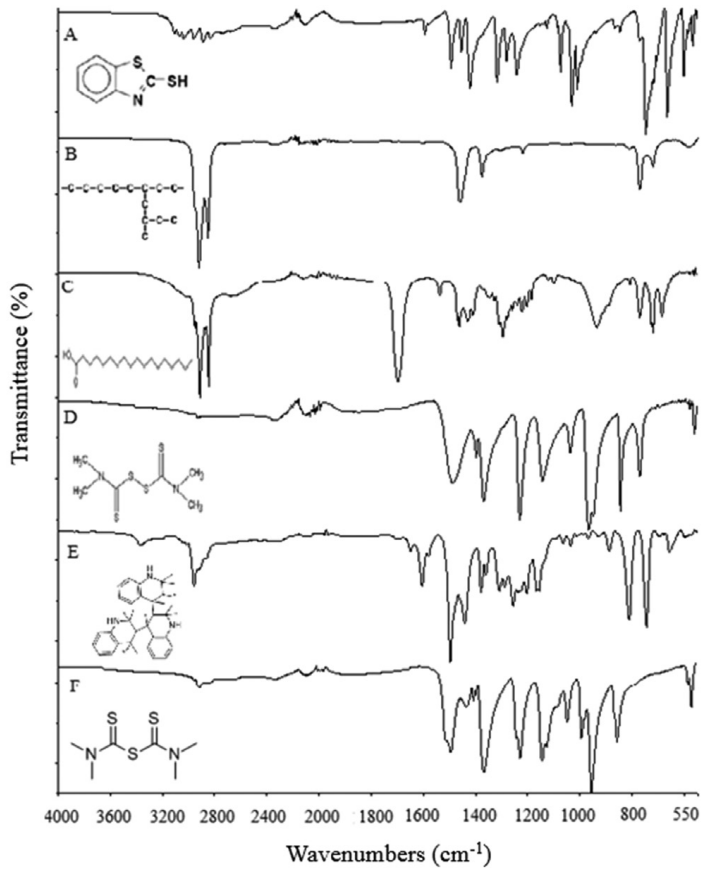

Figure 1. UATR spectra of organic additives of EPDM compositions 1 and 2: (A) MBT; (B) paraffinic oil; (C) stearic acid; (D) TMTD; (E) TMQ; (F) TMTM. 


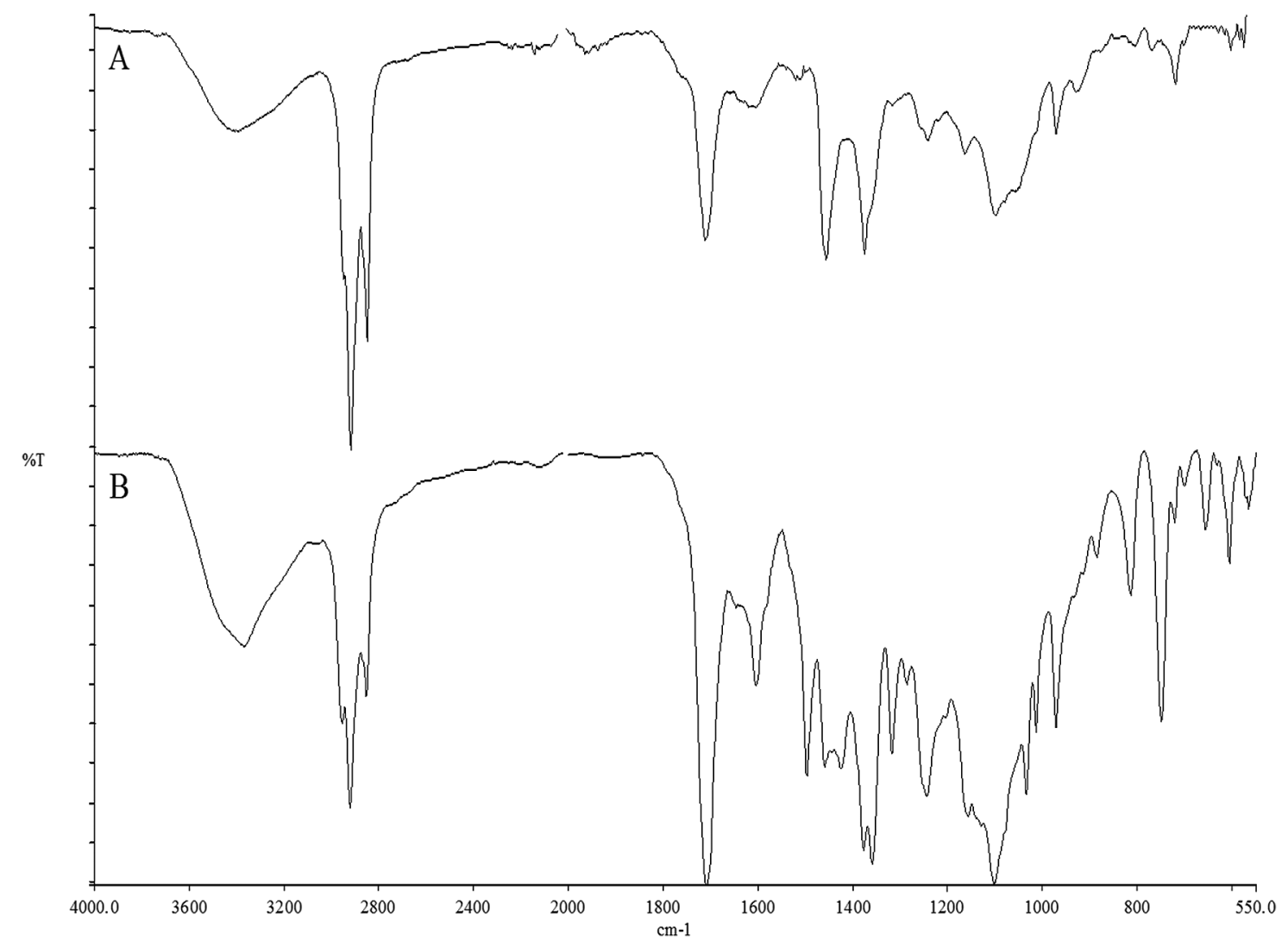

Figure 2. Spectra UATR of extraction residue in acetone, of EPDM compositions: (A) 1; (B) 2.

It should be recorded that the spectra of Figure 2 is different and may already be a sign that are associated to different compositions, constituting a first information and support to analysis, if they were analyzing unknown compositions, for example.

\subsection{TLC analysis of EPDM compositions}

3.3.1 Composition 1 - TLC system: eluent containing 70\% hexane, 30\% ethyl ether and 5\% acetic acid / Gibbs developer (Bukhina et al. ${ }^{[14]}$ )

Figure 3 shows the chromatography plate of composition 1, after using the TLC system mentioned.

The RFs and colors of spots, shown in Figure 3 already mentioned, are included in Table 2. Usually referred call the first eluted deposit of each sample, 1 , and to give sequential numbers to others, for this and the other composition .Although there is no very clear separation of colors, very clear, can be seen that the sample extract showed basically an eluted deposit. Additives showed two eluted spots, each showing good repeatability in color and RF. The stearic acid showed one eluted deposit. There is an indication, the $\mathrm{RF}$ values and colors, that both paraffinic oil (higher RF) and MBT (RF around 0.4 ) would be present in the sample extract, but there is need for the IR analysis to try to confirm the indication TLC analysis.

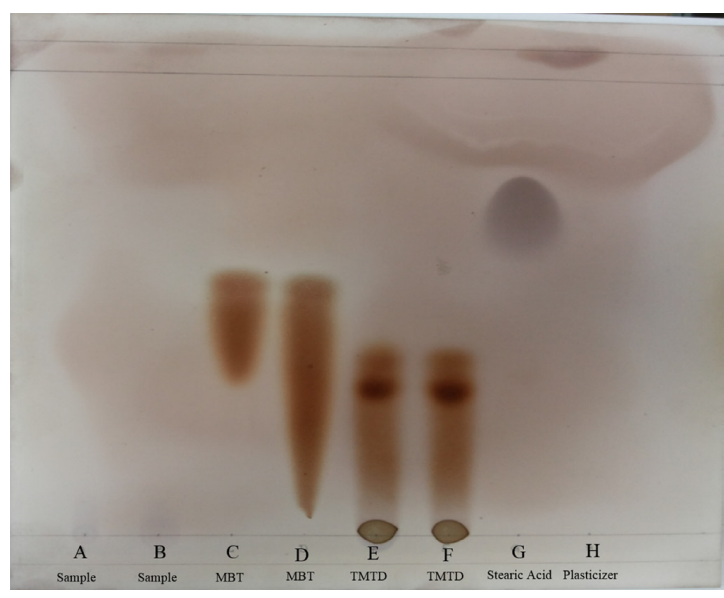

Figure 3. Composition 1 - TLC system: mixture of $70 \%$ hexane, $30 \%$ ethyl ether and 5\% acetic acid in a ratio of 70:30:5 and Gibbs reagent as developer.

3.3.2 Composition 2 - TLC system: eluent containing 70\% hexane, 30\% ethyl ether and 5\% acetic acid / Gibbs developer (Bukhina et al. ${ }^{[14]}$ )

Figure 4 shows the chromatography plate of composition 2, after using the TLC system above named.

The RFs and colors of spots, shown in Figure 4 cited above, are included in Table 3. It is observed that there was 
Table 2. TLC system - Composition 1: eluent of 70\% hexane, 30\% ethyl ether and 5\% acetic acid), after using Gibbs' reagent - spots of the composition extract and their additives.

\begin{tabular}{lccc}
\hline \multicolumn{1}{c}{ Sample } & $\begin{array}{c}\mathbf{N}^{0} \text {. Eluted } \\
\text { dep. }\end{array}$ & $\begin{array}{c}\text { RF } \\
\text { calculated }\end{array}$ & Colour \\
\hline A - acetone extract & 1.0 & 1.00 & light red \\
B - acetone extract & 1.0 & 1.00 & light red \\
acetone extract - & 1.0 & 0.31 & light brown \\
middle of the plate & & & \\
C - MBT & 1.0 & 0.37 & dark brown \\
& 2.0 & 0.47 & light brown \\
D - MBT & 1.0 & 0.25 & dark brown \\
& 2.0 & 0.47 & light brown \\
E - TMTD & 1.0 & 0.14 & light brown \\
& 2.0 & 0.25 & dark brown \\
F - TMTD & 1.0 & 0.14 & light brown \\
& 2.0 & 0.25 & dark brown \\
G - Stearic acid & 1.0 & 0.65 & dark beige \\
H - Paraffinic oil & 1.0 & 1.00 & light beige \\
\hline
\end{tabular}

Table 3. TLC system- Composition 2: mixture of $70 \%$ hexane, $30 \%$ ethyl ether and 5\% acetic acid in a ratio of 70:30:5 and Gibbs reagent as developer - spots of the composition extract and their additives.

\begin{tabular}{lccc}
\hline \multicolumn{1}{c}{ Sample } & $\begin{array}{c}\text { No. eluted } \\
\text { dep. }\end{array}$ & $\begin{array}{c}\text { RF } \\
\text { calculated }\end{array}$ & Colour \\
\hline \multirow{3}{*}{ A - Acetone extract } & 1 & 0.03 & Blue \\
& 2 & 0.2 & Blue \\
& 3 & 0.25 & Brown \\
& 4 & 0.38 & Brown \\
& 5 & 0.44 & Blue \\
B - Stearic acid & 6 & 0.69 & Blue \\
C - Paraffin oil & 1 & 0.53 & Light beige \\
D - MBT & 1 & 0.78 & Light brown \\
& 1 & 0.2 & Reddish \\
E - TMQ & & & Brown \\
& 1 & 0.1 & Blue \\
& 2 & 0.44 & Blue \\
F - TMTM & 3 & 0.69 & Blue \\
\hline
\end{tabular}

a clearer separation, color and RF. In this plate, in addition to the additives already discussed in another composition and that are common to both, there was also the addition of TMQ and TMTM, components of the composition 2. There is an indication by the RF values and colors, as well MBT would TMQ present in the sample extract, but there is also need for the IR analysis, as mentioned for other formulation to try to confirm the indication of TLC analysis.

\subsection{TLC/IR off-line coupling of EPDM compositions}

$\mathrm{TLC} / \mathrm{IR}^{[2]}$ methodology consists basically in assessing the existence of spots of rubber extract with colors and RF similar to those of organic additives, the chromatographic

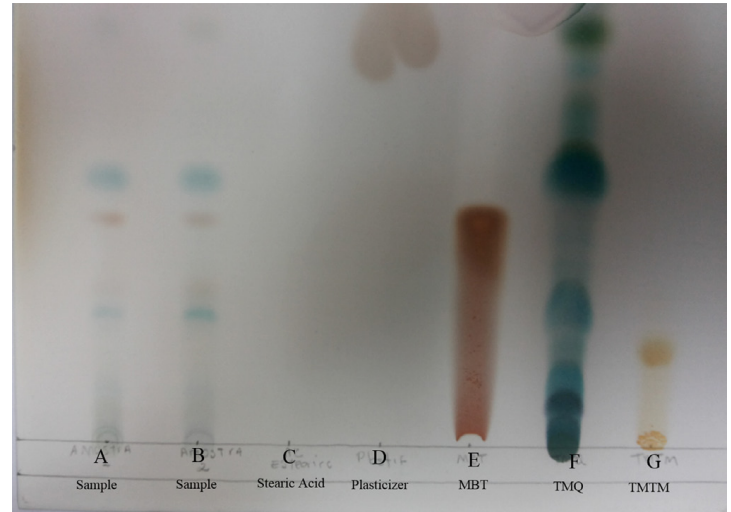

Figure 4. Composition 2 - TLC system: mixture of $70 \%$ hexane, $30 \%$ ethyl ether and 5\% acetic acid in a ratio of 70:30:5), and Gibbs reagent as developer.

plate studied, shave them, trying to eliminate interference of the board of silica and obtaining IR spectra of these spots, effecting thereby a comparison spectra, in order to characterize the additives present in the formulation. Therefore, the spectra shown below are for the comparison made for both EPDM formulations. It must be remembered that the characterization of inorganic additives, if necessary, is made separately for simple calcination ${ }^{[2]}$

- Composition 1: Figure 5 shows the UATR spectra of spots of extracts the A and B rubber, compared to others of the TMTD, stearic acid, paraffin oil and MBT, also suggested by UATR analysis of the rubber extract or by TLC analysis. In this figure and in the other composition, were marked only the bands that distinguish the functional groups of the compounds, preventing common absorptions noted $\mathrm{CH}_{2}$ and $\mathrm{CH}_{3}$ groups, and some that are in regions close to the $\mathrm{CS}$ as $\mathrm{CN}$, around $1150 \mathrm{~cm}^{-1}$, in order to facilitate the visualization of bands and explanation of the data. However, it can be noted that the spectrum of the extracts A and B - middle of the plate, shows similarity with the shape of absorptions of sulfur compounds, even though in a smaller proportion in the formulation.

Basically, it can be said that were observed bands $\left(\mathrm{cm}^{-1}\right)$ of stearic acid, about $1700(\mathrm{C}=\mathrm{O})$ and $1300(\mathrm{CO}), \mathrm{MBT}$, around 3070 to 1600 (Ar-H and Ar-C); TMTD of around $1240(\mathrm{C}=\mathrm{S}, \mathrm{CS})$, and 560 (SS); of paraffin oil, around 720, confirming the information of UATR and TLC analysis of extract of this composition.

- Composition 2: Spectra were obtained from different RF composition extract, but some were not well resolved probably due to the small quantity of sample. There were in others interference of silica, and basically, additives which might be characterized were stearic acid (bands around $1700 \mathrm{~cm}^{-1}(\mathrm{C}=\mathrm{O})$ and $1300 \mathrm{~cm}^{-1}$ (CO), and TMQ (bands around $3380 \mathrm{~cm}^{-1}(\mathrm{NH})$ and $741 \mathrm{~cm}^{-1},(\mathrm{ArC})$ as shown in Figure 6. 


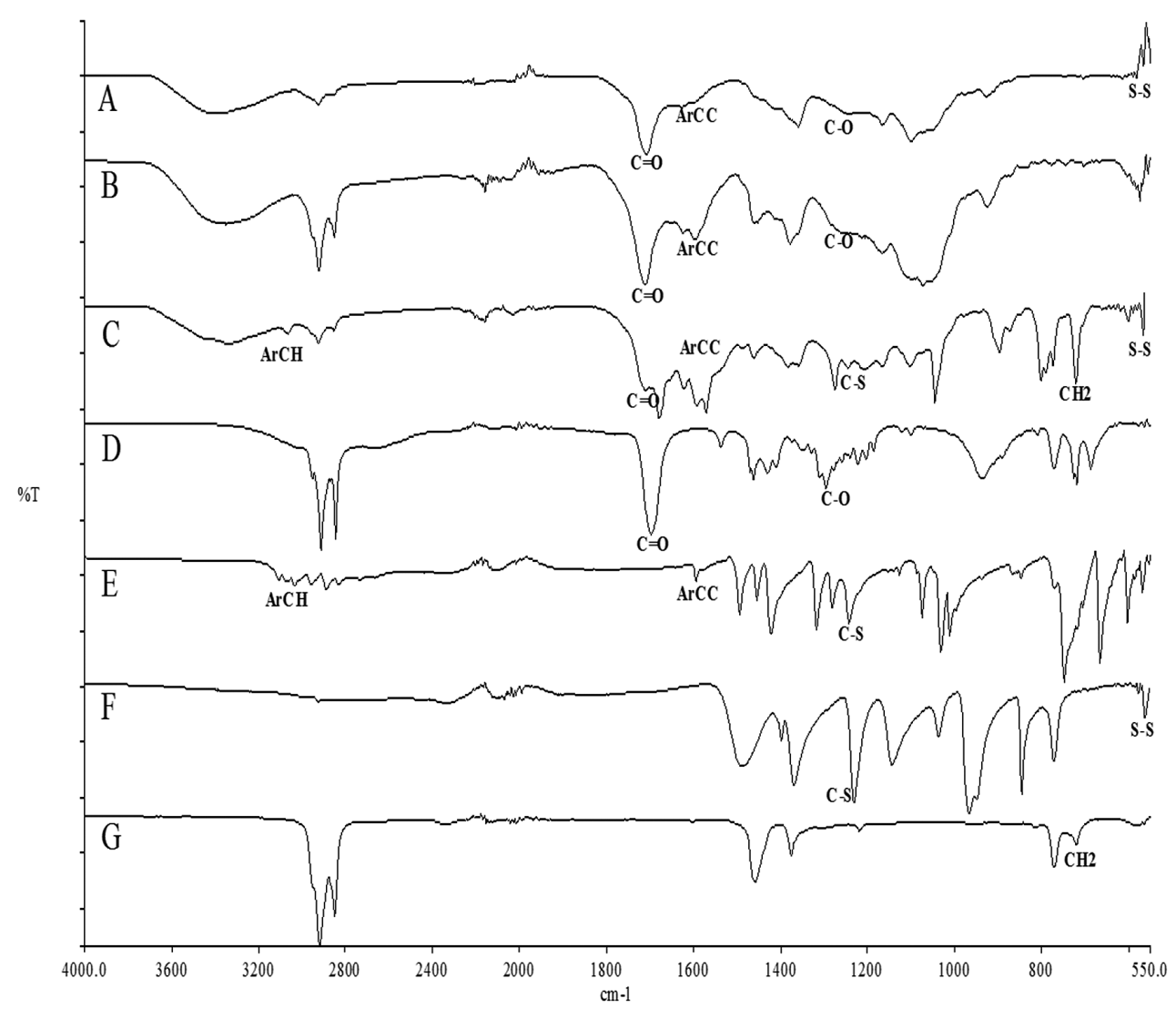

Figure 5. UATR Spectra of spots of the composition 1: (A) A RF1; (B) B, RF1; (C) A and B - middle of the plate; (D) stearic acid; (E) MBT; (F) TMTD; (G) paraffinic oil.

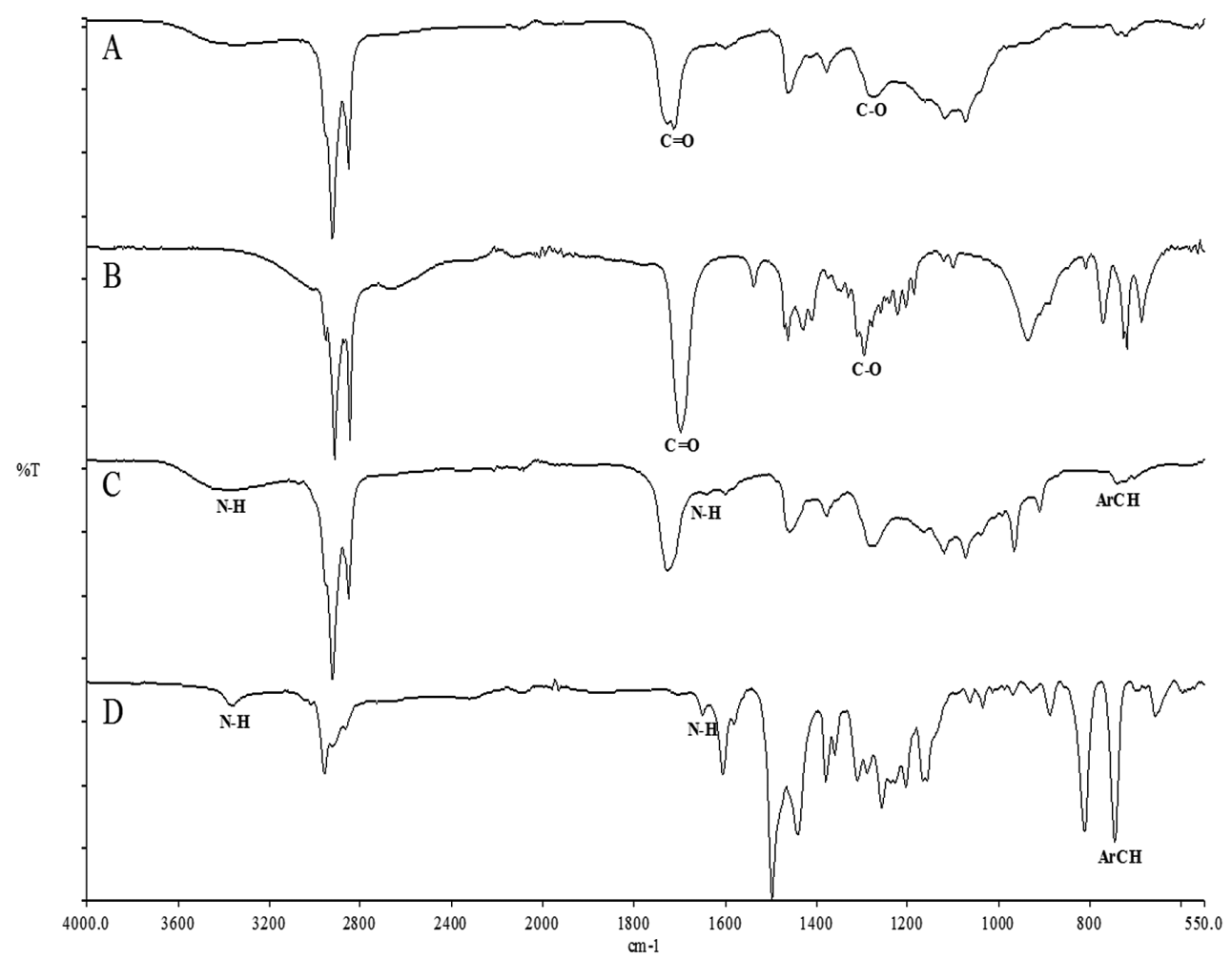

Figure 6. UATR spectra of spots of the composition 2): A and B, RF5; (B) stearic acid; (C) A and B, RF2; (D) TMQ. 


\section{Conclusions}

TLC/IR (UATR) off-line coupling showed that it is possible to separate and identify some additives, even in small quantities in the EPDM compositions analysed, by a simple and fast IR methodology, without interference of silica IR bands, as observed by the others more complex techniques such as HPLC/IR or TLC/IR (DRIFT or Microscopy/FT-IR).

Thus, it is possible to suggest that this methodology could be applied for detection of organic additives of similar chemical structures, even in small quantities present in the rubber composition.

\section{References}

1. Crompton, R., \& Crompton, T. R. (2007). Determination of additives in polymers and rubbers. Southport: Smithers Rapra Publishing.

2. Dutra, R. C. L. (1996). Aplicação de técnica TLC-IR em estudos de separação, identificação e quantificação de aditivos em borrachas. Polímeros: Ciência e Tecnologia, 6(2), 26-31. Retrieved in 13 February 2015, from http://revistapolimeros. org.br/files/v6n2/v6n2a01.pdf

3. Striegel, M. F., \& Hill, J. (1996). Thin-layer chromatography for binding media analysis (Scientific Tools for Conservation). Los Angeles: Getty Conservation Institute. Retrieved in 13 February 2015, from http://hdl.handle.net/10020/gci_pubs/ thin_layer_chromatography

4. Smith, A. L. (1979). Applied infrared spectroscopy. New York: John Wiley \& Sons.

5. Sanches, N. B., Cassu, S. N., Diniz, M. F., Dutra, R. C. L. (2014). Characterization of additives typically employed in EPDM formulations by using FT-IR of gaseous pyrolyzates. Polimeros: Ciência e Tecnologia, 24(3), 269-275. http://dx.doi. org/10.4322/polimeros.2014.066.

6. Santos, R. P., Oliveira, M. S., Mattos, E. C., Diniz, M. F., \& Dutra, R. C. L. (2013). Study by FT-IR technique and adhesive properties of vulcanized EPDM modified with plasma. Journal of Aerospace Technology and Management, 5(1), 65-74. http:// dx.doi.org/10.5028/jatm.v5i1.162.

7. Santos, R. P., Oliveira, M. S. Mattos, E. C.; Diniz, M. F.; Dutra, R. C. L. (2012). Caracterização por FT-IR da superfície de borracha EPDM tratada via plasma por micro-ondas. Polímeros: Ciência e Tecnologia, 22(5), 440-446. http://dx.doi.org/10.1590/ S0104-14282012005000065.

8. Dutra, R. C. L., \& Montenegro, A. M. C. (1987). Análise de aditivos em borrachas. In: Anais do I Seminário de Caracterização de Sistemas Poliméricos. Rio de Janeiro.

9. He, W., Shanks, R., \& Amarasinghe, G. (2002). Analysis of additives in polymers by thin-layer chromatography coupled with Fourier transform-infrared microscopy. Vibrational Spectroscopy, 30(2), 147-156. http://dx.doi.org/10.1016/ S0924-2031(02)00024-3.

10. Cserháti, T., Forgács, E., Candeias, M., Vilas-Boas, L., Bronze, R., \& Spranger, I. (2000). Separation and tentative identification of the main pigment fraction of raisins by thinlayer chromatography-fourier transform infrared and highperformance liquid chromatography-ultraviolet detection. Journal of Chromatographic Science, 38(4), 145-150. http:// dx.doi.org/10.1093/chromsci/38.4.145. PMid:10766480.

11. Liu, J., Zhou, F., Guo, R., Jiang, Y., Fan, X., He, A., Zhai,Y., Weng, S., Yang, Z., Xu,Y., Noda, I., Wu, J. (2014). Analysis of an alanine/arginine mixture by using TLC/FTIR technique. Journal of Spectroscopy, 2014, 1-4. http://dx.doi. org/10.1155/2014/925705.

12. American Society for Testing and Materials - ASTM. (2013). ASTM D3568-03: standard test methods for rubber: evaluation of EPDM (Ethylene Propylene Diene Terpolymers) including mixtures with oil. West Conshohocken. Reapproved 2009.

13. Wake, W. C., Tidd, B. K., \& Loadman, M. J. R. (1983). Analysis of rubber and rubber-like polymer. 3rd ed. New York: Applied Science.

14. Bukhina, M. F., Morozov, Y. L., van de Ven, P. M., \& Noordermeer, J. W. M. (2003). Mould fouling of EPDM rubber compounds. KGK Kautschuk Gummi Kunststoffe, 56(4), 172-183. Retrieved in 13 February 2015, from: http://www.kgk-rubberpoint.de/ ai/resources/e907ea3cdb1.pdf

15. Wolfang, W. (1987). Tópicos de espectroscopia no infravermelho. São José dos Campos: ITA.

Received: Feb. 13, 2015

Revised: July 20, 2015

Accepted: Oct. 01, 2015 